\title{
CONFUSÃO DE LÍNGUAS, TRAUMA E HOSPITALIDADE EM SÁNDOR FERENCZI ${ }^{1}$
}

\author{
Alan Osmo \\ Daniel Kupermann ${ }^{\#}$
}

\begin{abstract}
RESUMO. Neste trabalho discutimos as ideias de confusão de línguas, de trauma e de hospitalidade no campo psicanalítico. Para Ferenczi, a relação adulto-criança é marcada por uma confusão decorrente de uma diferença de línguas, de forma que muitas vezes um não entende o outro. Nesse contexto, é possível a emergência do trauma patogênico. A experiência analítica, ao invés de levar o acontecimento traumático a domínios psíquicos melhores, pode reproduzir e até agravar o que foi vivido como catastrófico na infância. Neste sentido, o princípio de hospitalidade na clínica analítica é de suma importância para se evitar uma possível reprodução do trauma entre analista e analisando. Neste artigo utilizamos como referência principal a obra de Sándor Ferenczi, estabelecendo relações em alguns pontos com textos de Jacques Derrida e de Walter Benjamin, que discutem a origem da confusão de línguas e o problema da possibilidade da tradução.

Palavras-chave: Ferenczi, Sandor; trauma psíquico; hospitalidade.
\end{abstract}

\section{CONFUSION OF TONGUES, TRAUMA AND HOSPITALITY IN SÁNDOR FERENCZI}

\begin{abstract}
In this paper, we discuss the ideas of confusion of tongues, trauma and hospitality in the field of psychoanalysis. For Ferenczi, the adult-child relationship is marked by a sort of confusion due to a difference of tongues (languages), which makes that often one does not understand the other. In this context, it is possible the emergence of the pathogenic trauma. The analytic experience can, instead of bringing the traumatic event to better psychic layers, produce again or even aggravate what was experienced as trauma in the childhood. In this sense, the principle of hospitality presents itself as crucial in order to prevent a possible reproduction of the trauma between analyst and analysand. In this article we used as main reference the work of Sandor Ferenczi, establishing relations at some points with texts from Jacques Derrida and Walter Benjamin, which discuss the origin of the confusion of tongues and the problem of the possibility of translation.
\end{abstract}

Key words: Ferenczi, Sandor; psychic trauma; hospitality.

\section{CONFUSIÓN DE LENGUAS, TRAUMA Y HOSPITALIDAD EN SÁNDOR FERENCZI}

RESUMEN. En este trabajo se discuten los conceptos de confusión de lenguas, trauma y hospitalidad en el campo del psicoanálisis. Para Ferenczi, la relación adulto-niño está marcada por una confusión debido a una diferencia de lenguas, lo que hace que a menudo uno no entienda al otro. En este contexto, es posible la aparición del trauma patógeno. La experiencia analítica puede, en lugar de llevar el acontecimiento traumático a un mejor plano psíquico, reproducir e incluso empeorar lo que se vivió como un trauma en la infancia. En este sentido, el principio de la hospitalidad se presenta como crucial en la clínica psicoanalítica con el fin de evitar la posible reproducción del trauma entre analista y analizando. En este artículo, hemos utilizado como principal referencia la obra de Sándor Ferenczi, estableciendo relaciones en algunos puntos con textos de Jacques Derrida y de Walter Benjamin, que discuten el origen de la confusión de lenguas y el problema de la posibilidad de traducción.

Palabras-clave: Ferenczi, Sandor; trauma psiquico; hospitalidad.

\footnotetext{
Apoio: Fapesp.

Psicólogo, formado pela Universidade de São Paulo.

\# Professor doutor do Departamento de Psicologia Clínica do Instituto de Psicologia da Universidade de São Paulo (USP), psicanalista membro da Formação Freudiana do Rio de Janeiro.
} 


\section{BABEL E A CONFUSÃo DE LÍNGUAS}

Em Torres de Babel, o filósofo Jacques Derrida realiza uma leitura do mito bíblico. Para Derrida (2006), essa história "conta, entre outras coisas, a origem da confusão de línguas, a multiplicidade dos idiomas, a tarefa necessária e impossível da tradução, sua necessidade como impossibilidade" (pp. 20-21).

Gênesis 11 narra sobre um tempo em que todos os povos falavam uma só língua. A grande família semítica tinha o projeto, então, de edificar uma cidade e uma torre que se ergueria aos céus. Eles queriam dar a si mesmos "um nome", de modo que não fossem espalhados pela Terra. Deus reage a esse projeto: "Eis que o povo é um, e todos têm uma mesma língua; e isto é o que começam a fazer (...). Eia, desçamos e confundamos ali a sua língua, para que não entenda um a língua do outro" (Genêsis 11, 6-7).

Assim, a construção da cidade é interrompida: Deus dispersa os homens sobre a terra, clamando seu nome: Babel.

Acerca da multiplicidade de sentidos contida no nome Babel, Derrida retoma o artigo "Babel", presente no Dicionário Filosófico de Voltaire:

Não sei por que é dito na Gênese que Babel significa confusão; pois $B a$ significa pai nas línguas orientais, e $\mathrm{Bel}$ significa Deus; Babel significa a cidade de Deus, a cidade santa. Os antigos davam esse nome a todas as suas capitais. Mas é incontestável que Babel quer dizer confusão, seja porque os arquitetos foram confundidos após terem erguido sua obra até oitenta e um mil pés judeus, seja porque as línguas se confundiram; e é desde esse tempo que os alemães não entendem mais os chineses (Voltaire, 1764, citado por Derrida, 2006, pp. 12-13).

Babel, como diz Derrida (2006), além de ser um nome próprio, portanto intraduzível, quer dizer confusão em ao menos dois sentidos: o da confusão de línguas e o do estado de confusão dos arquitetos diante da estrutura interrompida; mas Babel quer dizer ainda o nome do pai, ou mais precisamente, o nome de Deus como nome do pai: "Dando seu nome, dando todos os nomes, o pai estaria na origem da linguagem e esse poder pertenceria de direito a Deus o pai. E o nome de Deus o pai seria o nome dessa origem das línguas" (p.14). Mas é também Deus, que ao mesmo tempo desune as línguas, semeando a confusão entre os homens, ou seja, que aparece na origem da multiplicidade dos idiomas. Consequentemente, como afirma Derrida, Deus "impõe e interdiz ao mesmo tempo a tradução" (p.18).

De que Deus pune os homens ao fazer isso? Para Derrida (2006), o projeto de construção da cidade e da torre que se ergueria aos céus, pela grande família semítica, tinha como pretensão impor ao universo seus recém-fundados império e língua. Eles queriam com essa construção fazer a si "um nome", assegurando assim "uma genealogia única e universal" (p.17). Deus interrompe esse projeto impondo seu nome; as línguas, então, se dispersam, se confundem, se multiplicam.

A partir do ensaio de Derrida, podemos pensar a confusão de línguas como algo que aparece inevitável desde a instauração de uma origem das línguas; mas também como o que vai exigir a tarefa de tradução, ainda que obrigando ao tradutor uma certa renúncia. ${ }^{2}$

Esta leitura do mito bíblico de Babel nos pareceu um ponto de partida interessante para introduzir este artigo, no qual procuramos discutir as ideias de confusão de línguas, de trauma e de hospitalidade no terreno da psicanálise. O percurso adotado parte da reflexão acerca da relação do adulto com a criança em um contexto traumático, avança problematizando a relação do analista com o analisando na situação analítica e o que nesta pode reproduzir e até agravar o que foi vivido como trauma na infância; e, por fim, conclui referindo-se à relação entre o bebê e o ambiente que o acolhe, na qual a dimensão da hospitalidade aparece como fundamental. Utilizamos como referência principal a obra do psicanalista húngaro Sándor Ferenczi, estabelecendo relações, em alguns pontos, com textos de Jacques Derrida e de Walter Benjamin que discutem a origem da confusão de línguas e o problema da possibilidade da tradução.

\section{CONFUSÃO DE LÍNGUAS EM FERENCZI}

A ideia de confusão de línguas é abordada por Ferenczi em um polêmico texto intitulado Confusão de língua entre os adultos e a criança (A linguagem

2 Em sua tradução do texto Die Aufgabe des Ubersetzers de Walter Benjamin (1923/2008), Susana K. Lages explicita que há uma ambiguidade de sentidos no termo Aufgabe, que poderia ser tanto entendido como tarefa, quanto por renúncia. 
da Ternura e da Paixão), de 1933. É importante situála em relação à noção de trauma, que tem grande relevância na obra do autor, no que diz respeito a aspectos tanto teóricos quanto clínicos (Ferenczi os via como indissociáveis). Tentaremos, mais adiante, esboçar uma diferenciação entre confusão de línguas e trauma, apesar de o autor não chegar a realizá-la explicitamente.

No texto mencionado, Ferenczi (1933/1992) conta como habitualmente aconteceria uma sedução incestuosa de uma criança por parte de um adulto:

\begin{abstract}
Um adulto e uma criança amam-se; a criança tem fantasias lúdicas, como desempenhar um papel maternal em relação ao adulto. $\mathrm{O}$ jogo pode assumir uma forma erótica, mas conserva-se, porém, sempre no nível da ternura. Não é o que se passa com os adultos se tiverem tendências psicopatológicas... Confundem as brincadeiras infantis com os desejos de uma pessoa que atingiu a maturidade sexual, e deixam-se arrastar para a prática de atos sexuais sem pensar nas consequências (pp.101-102).
\end{abstract}

Os casos em que se pratica uma violência sexual contra a criança têm como pano de fundo uma confusão decorrente de uma diferença de línguas entre o adulto e a criança: de um lado há o jogo que acontece ao nível da ternura e, do outro, os desejos de um adulto que atingiu a maturidade sexual. A sedução incestuosa acontece quando o adulto confunde a ternura infantil com amor sensual.

Para ilustrar o problema da confusão de línguas de outra forma, podemos evocar o que Ferenczi (1933/1992) chama de punição passional:
Os delitos que a criança comete, de brincadeira, só passam a ter um caráter de realidade pelas punições passionais que recebem de adultos furiosos, rugindo de cólera, o que acarreta numa criança, não culpada até então, todas as consequências da depressão (p.104).

Esta citação se refere a casos em que a criança pratica inocentemente um "delito" e é punida excessivamente por um adulto sem controle. Apenas a partir de então apareceria nela o sentimento de culpa, algo que seria próprio do adulto.

Tanto nos casos de sedução incestuosa quanto nos de punição passional, discutidos por Ferenczi, parece que há um confronto entre duas línguas que teriam qualidades distintas, uma confusão promovida por conta de uma dissimetria entre o mundo do adulto e o mundo da criança. Como escreve Ferenczi (1928/1992a), “o que escapa precisamente aos pais é o que para as crianças é o óbvio; e o que as crianças não percebem é claro como o dia para os pais" (p.8). Ferenczi dá o nome de língua da paixão ao que seria próprio da onipotência narcísica do adulto, e o de língua da ternura ao que seria da ordem da ilusão de onipotência lúdica infantil. ${ }^{3}$ Sobre a diferença da natureza entre elas, é importante salientar que o próprio autor, no pós-escrito do referido texto, diz que é um problema que continua em suspenso.

Pinheiro (1995), ao comentar esse tema, assinala alguns pontos importantes. $O$ adulto da paixão é aquele que perde seus limites. A palavra paixão seria empregada por Ferenczi em um sentido de exagero ou de abuso, típico do psicótico. Não que essa paixão seja propriedade exclusiva de psicóticos, pois ela pode estar presente em qualquer adulto em algum momento de sua relação com a criança: trata-se de "um comportamento efetivo, de fato apaixonado, desmesurado, louco" (p. 71).

Do outro lado há a ternura, que não conhece o exagero da desmesura. Ela deve ser entendida não como ausência de sexualidade, mas como anterior à sexualidade sob o primado genital. A língua da ternura, que é a própria da criança, é a língua do lúdico. Sobre isto escreve Ferenczi (1930/1992b): "O que a criança deseja, de fato, mesmo no que diz respeito às coisas sexuais, é somente o jogo e a ternura, e não a manifestação violenta da paixão" (p.64).

A ideia de confusão de línguas parece colocar em jogo o problema da multiplicidade de línguas. Muitas vezes os adultos e as crianças não falam a mesma língua, eles são estrangeiros entre si.

\section{O TRAUMA E SUAS CONSEQUÊNCIAS}

É importante, neste contexto, aprofundarmos uma das problemáticas centrais em Ferenczi: o trauma patogênico ${ }^{4}$. Esse tipo de trauma acontece em dois

O termo alemão Sprache pode ser traduzido tanto por língua quanto por linguagem. Neste trabalho, optamos pela tradução por língua.

4 O conceito de trauma é compreendido de diferentes maneiras na psicanálise, conforme a abordagem teórica de cada autor. Alguns autores privilegiam uma dimensão estruturante do trauma, constitutiva da subjetividade e inevitável, devido à necessária inserção do sujeito no campo da cultura e da linguagem (cf. Lacan, 1953/1998; cf. 
tempos. Podemos chamar o primeiro momento de choque. Trata-se de um acontecimento em que se age de forma esmagadora sobre o sujeito, de maneira que ele não pode oferecer resistência. É importante procurar não restringir esse acontecimento a um determinado tipo de experiência, apesar de o próprio Ferenczi se referir muitas vezes a experiências de sedução incestuosa, de punição passional, ou de abandono.

O choque sobrevém sempre sem preparação, ele tem o caráter de algo súbito e equivale à "aniquilação do sentimento de si, da capacidade de resistir, agir e pensar com vistas à defesa do si mesmo" (Ferenczi, 1934/1992c, p.109). Diante do grande desprazer gerado, uma possibilidade de escape é oferecida pela autodestruição: uma "desorientação psíquica", gerada pela destruição do que mantém a coesão das formações psíquicas em uma entidade. Isto gera uma suspensão de toda a espécie de atividade psíquica, aí incluída também a percepção.

Durante esse estado de paralisia sensorial "aceitar-se-á sem resistência toda impressão mecânica e psíquica" e "nenhum traço mnêmico subsistirá dessas impressões", de sorte que as origens do choque se tornarão inacessíveis à memória. "Contra uma impressão que não é percebida não há defesa possível” (Ferenczi, 1934/1992c, p.113).

Não obstante, como escreve Ferenczi (1932/1990), após o choque a vítima ainda pode ser socorrida. A criança está confusa, ela nada pode dizer sobre o que aconteceu. Por conta disso ela vai buscar junto a alguém de confiança algum sentido, ou ao menos um testemunho. É aí então que pode ocorrer o segundo momento do trauma: o desmentido.

É importante ressaltar esse ponto, pois um dos aspectos fundamentais da teoria do trauma de Ferenczi (1934/1992c) é que o "comportamento dos adultos em relação à criança que sofreu o traumatismo faz parte do modo de ação psíquica do trauma" (p.111). As possíveis reações dos adultos, no sentido de produzir o traumático na criança, seriam: dar provas de

Laplanche, 1988); porém a maioria dos comentadores de Ferenczi privilegiam o estatuto desestruturante do trauma, que produz efeitos catastróficos para a subjetividade (cf. Haynal, 1995; cf. Kupermann, 2006; cf. Sabourin, 1988). Neste caso, considera-se o trauma vinculado às vicissitudes da história de vida e das relações estabelecidas pelo sujeito com o ambiente em que vive. Nesse artigo, utilizamos o termo trauma patogênico, como aparece na obra ferencziana, para evitar uma possível confusão com a concepção de trauma estruturante. incompreensão; punir a criança; exigir dela um heroísmo da qual ela ainda não é capaz; ou reagir com um silêncio mortífero.

De qualquer forma, essa atitude dos pais ou dos adultos cuidadores é a de que "não aconteceu nada", desautorizando a versão da criança. As alusões da criança acabam sendo ignoradas ou tratadas como irrelevantes e, "diante disso, a criança cede e deixa de poder sustentar sua própria opinião a tal respeito" (Ferenczi, 1932/1990, p.58). Será justamente o desmentido que tornará o trauma patogênico: "O pior é realmente a negação, a afirmação de que não aconteceu nada, de que não houve sofrimento ou até mesmo ser espancado e repreendido quando se manifesta a paralisia traumática dos pensamentos ou dos movimentos", lemos em Ferenczi (1931/1992d, p.79).

Por outro lado, Ferenczi (1931/1992d) observa: "Tem-se mesmo a impressão de que esses choques graves são superados, sem amnésia nem sequelas neuróticas, se a mãe estiver presente, com toda a sua compreensão, sua ternura e, o que é mais raro, uma total sinceridade" (pp.79-80). Neste caso, em que a reação do adulto não é o desmentido, mas sim, a compreensão e o acolhimento, o trauma patogênico não acontece.

Assim, para acontecer o trauma são necessários os dois momentos: o do choque e o do desmentido. Mas como é possível saber se eles ocorreram?

Para Ferenczi, o acontecimento traumático permanece inacessível à memória de quem o vivenciou. São visíveis apenas as cicatrizes deixadas por ele no psiquismo. Nesse sentido, para nos aprofundarmos na noção de trauma em Ferenczi, convém nos determos um pouco no que seriam as suas consequências para o sujeito.

A defesa psíquica utilizada diante do traumatismo é a clivagem narcísica. Uma das partes da personalidade que foi clivada "sobrevive em segredo e esforça-se constantemente por manifestar-se", (Ferenczi, 1930/1992b, p. 65). A metáfora utilizada por Ferenczi para ilustrar esse mecanismo é a de que em uma parte do corpo se abrigariam "as parcelas de um gêmeo que foi inibido”. A outra parte, a que foi poupada, assumiria o trabalho de adaptação à realidade.

Tudo se passa como se, em decorrência do processo traumático, a relação de objeto, tornada impossível, fosse bruscamente transformada em uma 
relação narcísica. Ferenczi (1934/1992c) assim se refere um "homem abandonado pelos deuses":

\begin{abstract}
Se até aqui esteve privado de amor, inclusive martirizado, desprende agora um fragmento de si mesmo que, sob a forma de pessoa dispensadora de cuidados, prestimosa..., sente piedade da parte restante e atormentada da pessoa, cuida dela, decide por ela... Ela é a própria bondade e inteligência, um anjo da guarda, por assim dizer. Esse anjo vê desde fora a criança que sofre, ou que foi morta... percorre o mundo inteiro em busca de ajuda, imagina coisas para a criança que nada pode salvar (p.117).
\end{abstract}

Tem-se aqui o mesmo mecanismo do qual a criança abandonada lança mão que Ferenczi (1931/1992d) descreve em Análises de crianças com adultos. Uma parte de sua própria personalidade "começa a desempenhar o papel da mãe ou do pai com a outra parte", de forma a tornar o abandono nulo ou sem efeito (p.76); ou seja, um fragmento passa a desempenhar um papel de "instância autoperceptiva" que quer acudir em ajuda.

Essa clivagem marca também a divisão da subjetividade em uma parte sensível, brutalmente destruída, e uma parte que "sabe tudo mas nada sente" (Ferenczi, 1931/1992d, p.77). Cabe destacar, como consequência desse processo, a relação que se passa a ter com o corpo. Este fica anestesiado, entregue. O sujeito passa a vê-lo como se estivesse do lado de fora, como se todo o sofrimento e dor fosse infligido a outro ser (Ferenczi, 1932/1990).

Outra consequência importante do trauma patogênico é a identificação com o agressor. Ferenczi (1933/1992) vai levantar a hipótese de que, diante de uma experiência de violência ou sedução, a criança, que tem a personalidade ainda fracamente desenvolvida, "reage ao brusco desprazer, não pela defesa, mas pela identificação ansiosa e a introjeção daquele que a ameaça e agride" (p.103). Ela se converte em um ser que obedece mecanicamente ou que se fixa em uma atitude obstinada.

Diante da força e autoridade esmagadora dos adultos, as crianças sentem-se inibidas por um medo intenso. Esse medo, quando atinge seu ponto culminante, "obriga-as a submeter-se automaticamente à vontade do agressor, a adivinhar o menor dos seus desejos, a obedecer esquecendose de si mesmas" (Ferenczi, 1933/1992, p.102) e, por fim, a identificarem-se com ele. Nesta identificação, o agressor "desaparece enquanto realidade exterior e torna-se intrapsíquico" (p.102), e, através da alucinação negativa, a agressão deixa de existir enquanto acontecimento real.

Segundo Pinheiro (1995), a identificação com o agressor, para Ferenczi, remete a uma imagem de invasão no ego da criança. "O agressor usurpa o espaço egóico e toma posse deste lugar como se assumisse a fala da criança ou ocupasse seu espaço psíquico" (p.83); ele torna-se o posseiro desse ego, ignorando o seu verdadeiro dono.

Para preservar o adulto idealizado que a agrediu, a criança se dispõe a clivar-se e "a tornarse culpada de algo que ela não conhece, de algo em que não percebeu nenhum mal" (Pinheiro, 1995, p.73). É mais suportável para a criança tornar-se, ela própria, a culpada, já que perder seu objeto idealizado neste momento equivale ao risco de aniquilamento ou despedaçamento psíquico.

Por fim, cabe destacar o que Ferenczi (1933/1992) denomina progressão traumática. Esta é descrita como uma prematuração patológica de parte da personalidade, que acontece tal como a "maturidade apressada de um fruto bichado" (p.104). Trata-se da "eclosão surpreendente e súbita, como ao toque de uma varinha mágica, de faculdades novas" (p.104), que estavam aguardando tranquilamente o momento de expressar-se. Sob a pressão do trauma, a criança passa a manifestar os gestos mimetizados de um adulto.

É possível remeter-nos aqui a um sonho que Ferenczi (1931/1992d) diz acontecer com relativa frequência, ao qual deu o nome de "sonho do bebê sábio". Neste sonho, uma criança recém-nascida ou um bebê começa a falar de súbito, aconselhando sabiamente os pais e outros adultos, podendo se transformar em uma espécie de psiquiatra diante dos adultos e, como tal, ser obrigada a resolver os conflitos familiares e a carregar sobre seus ombros o fardo dos outros membros da família; porém isso tudo acontece à custa dos interesses próprios da criança, que perde sua espontaneidade.

A consequência, para o sujeito, dessa aquisição precoce de um saber e de uma maturidade própria dos adultos é um comprometimento da capacidade 
de afetar e ser afetado pelo outro, que se faz acompanhar de uma dificuldade de expressar afetos de amor e de ódio e de uma diminuição da potência para se afirmar de modo singular (Kupermann, 2006).

Algo que chama a atenção a partir do que foi exposto é que, para Ferenczi, em decorrência do trauma patogênico, não há, como se poderia esperar diante de uma ideia de adoecimento psíquico, algum tipo de paralisação ou regressão a formas de funcionamento mais arcaicas, mas sim, uma relativa adaptação à realidade. Diz o autor que "toda adaptação tem lugar numa pessoa que se tornou maleável pela dissociação devida ao terror" (Ferenczi, 1932/1990, p.50). Um sofrimento que é assim "superado" torna a pessoa mais prudente e mais paciente, porém isso pode acarretar uma restrição considerável da qualidade emocional da vida: "fica-se com a maior parte do interesse suspenso no outro mundo, e o fragmento restante é apenas forte para viver uma vida de rotina" (Ferenczi, 1932/1990, p.66).

\section{O DESMENTIDO TRAUMÁTICO E A TRADUÇÃO POSSÍVEL}

Vimos anteriormente que a confusão de línguas se impõe a nós como uma espécie de pano de fundo na relação entre os sujeitos e como destino explícito quando pensamos na relação adultocriança. Se, recuperando a narrativa de Babel, pensarmos a confusão de línguas como inevitável a partir da multiplicidade das línguas, como fica a questão do trauma?

O trauma patogênico não poderia ser simplesmente a confusão de línguas, pois, se assim fosse, qualquer relação em que ela se evidenciasse seria potencialmente traumática e acarretaria consequências patológicas ao sujeito. O que, então, distingue o trauma? E como, em meio à confusão, se evitar um trauma? Para buscar esclarecer essas questões, a noção de desmentido torna-se essencial.

Vimos anteriormente que para ocorrer o trauma são necessários dois momentos, Assim, ele pode ser evitado em seu aspecto patogênico desde que não haja o desmentido por parte da pessoa de confiança à qual se recorre em busca de sentido para a violação.
Sabourin (1988) ressalta que, caso sua reação seja o desmentido, são dois desmentidos que operam ao mesmo tempo: o desmentido pelo adulto da história factual, ou seja, do que aconteceu, e o desmentido da autonomia do pensamento da criança.

A esse respeito, Pinheiro (1995) aponta que a criança deposita "uma confiança cega no adulto". Essa confiança se vê ameaçada quando o adulto não corresponde às suas expectativas, ou seja, as de alguém que irá escutá-la, acreditar nela e ajudá-la a representar o que aconteceu. Diante desse desmentido a criança fica confusa: "Será o adulto ou será ela que não merece confiança?" (p.82).

Segundo esta autora, a criança só pode ter uma palavra própria quando esta é intermediada pela sua relação com o adulto. A princípio, ela toma palavras emprestadas do adulto e dirige a ele sua palavra para obter uma confirmação. "Este vaivém é condição imprescindível para que a criança conquiste sua própria palavra. É, portanto, por intermédio do adulto ... que a fala da criança pode ou não ter sua existência autorizada" (Pinheiro, 1995, p.74). Com o desmentido é produzida uma incompatibilidade simbólica. O desmentido assume o tom de uma verdade absoluta e, com isso, o que a criança fala passa a ser considerado como uma mentira absoluta.

Negando-se a autonomia do pensamento da criança e a sua palavra própria, impõe-se uma língua que tem um caráter único, universal, algo que podemos associar ao projeto de construção da torre, na narrativa de Babel, que tinha como pretensão impor ao universo um império e uma língua.

Como contraposição à concepção de desmentido traumático, recorremos a um ensaio de Walter Benjamin (1923/2008) sobre a tarefa do tradutor, no qual a questão da multiplicidade das línguas é pensada de outra maneira que não a da simples confusão e distância entre elas. Enquanto, com o desmentido, há uma sobreposição ou uma dominação de uma língua sobre outra a partir de uma pretensão de se tornar absoluta, total, Benjamin vai pensar em uma possível complementaridade das línguas.

Benjamin (1923/2008) sugere que uma língua se encontra em constante transformação. Até mesmo as palavras que já se fixaram em um texto 
têm sua "maturação póstuma", de forma que o tom e a significação se alteram ao longo do tempo. Uma língua tomada isoladamente permanece incompleta; aquilo que nela se quer dizer encontra-se oculto. Em todas as línguas e em todas as suas construções resta, além do comunicável, um elemento não comunicável. Não obstante, "as línguas não seriam estranhas umas às outras, sendo a priori - e abstraindo de todas as ligações históricas - afins naquilo que querem dizer" (p.70). Essa afinidade entre as línguas repousaria sobre o fato de que "em cada uma delas, tomada como um todo, uma só e a mesma coisa é designada" (p.72). Em sua pluralidade, as línguas se complementariam a partir da totalidade de suas intenções. Para Benjamin (1923/2008), a tradução tenderia a expressar o mais íntimo relacionamento das línguas entre si, ainda que ela seja "apenas um modo provisório de lidar com a estranheza das línguas" (p.73). Uma solução definitiva para essa estranheza permanece vedada aos homens.

Comentando Benjamin, Derrida (2006) ressalta que, em cada língua, visa-se algo que é também visado em outras línguas, mas nenhuma delas pode atingi-lo separadamente. Dessa maneira, é possível dizer que "cada língua está como que atrofiada em sua solidão, magra, parada no seu crescimento, enferma" (p.67). Seria a partir da tradução - ou seja, da suplementaridade linguística pela qual uma língua dá a outra o que lhe falta - que o cruzamento das línguas assegura o crescimento das línguas.

Propomos, neste trabalho, que o desmentido é aquilo que diferencia o trauma da confusão de línguas. Neste sentido, o trauma patogênico pode ser evitado em meio à confusão de línguas, já que as línguas, por mais estranhas que sejam entre si, podem se aproximar e se complementar sem que uma subjugue a outra. Trabalharemos, em seguida, essa questão a partir dos efeitos de significância almejados pela clínica psicanalítica.

\section{CONFUSÃO DE LÍNGUAS ENTRE OS ANALISTAS E O ANALISANDO}

Vimos anteriormente, acompanhando Ferenczi, a confusão de línguas presente na relação entre adulto e criança a partir das ideias de língua da ternura e língua da paixão. Em uma das anotações de seu Diário
Clínico $^{5}$, Ferenczi (1932/1990) parece estar atento também ao que poderíamos chamar de confusão de línguas na relação do analista com o analisando. Diz a nota: "Quem é louco, nós ou os pacientes? (As crianças ou os adultos?)" (p.129). Depreende-se dessa indagação uma segunda questão, que pode ser posta da seguinte maneira: pode a experiência psicanalítica ser traumatizante para o analisando?

Nesse comentário Ferenczi (1932/1990) realiza uma (auto)crítica implacável em relação ao método terapêutico da psicanálise, que teria se tornado cada vez mais impessoal, alertando para uma situação muito confortável, na qual o analista pode se acomodar. Muitas vezes o analista não percebe que uma grande parcela da resistência transferencial é artificialmente provocada por seu comportamento, que consiste em "flutuar como uma divindade" acima do paciente rebaixado ao nível de criança. $\mathrm{O}$ analista pode se deixar ficar por um longo tempo nessa posição de superioridade na qual é amado sem reciprocidade, numa situação semelhante à da megalomania infantil:

De um modo inteiramente inconsciente, o médico pode assim colocar-se, com toda a inocência consciente, em situação infantil em face do seu paciente. Uma parte do comportamento de um tal analista pode, com razão, ser qualificada de louca pelo paciente. Certas teorias do médico (ideias delirantes) não podem ser abaladas; se, no entanto, o paciente fizer isso, é um mau aluno, recebe uma nota baixa, está opondo "resistência" (pp.131-132).

Muitas vezes o "saber" do analista pode assumir, aos olhos do paciente, um caráter delirante; é um saber excessivo, que quer se colocar como verdadeiro, em contraposição a outro saber, o do analisando. Para Ferenczi (1932/1990), na própria loucura haveria um saber, já que o "louco" possui um olhar agudo para as paixões humanas. Em sua situação particular, ele estaria em uma "posição de conhecer um pouco dessa parte da realidade imaterial que nos é inacessível a nós materialistas" (p.67).

\footnotetext{
O Diário Clínico, escrito por Ferenczi (1932/1990) no último ano de sua vida, foi publicado apenas na década de 1980, ou seja, muito depois da sua morte. Nesse Diário, que tem um caráter inteiramente espontâneo, Ferenczi expressa ideias originais no campo teórico da psicanálise, profundos questionamentos ao dispositivo clínico tradicional, bem como divergências em relação ao próprio Freud.
} 
Então na clínica não seria inevitável a confusão de línguas quando o analista, imerso em um discurso teórico, dispõe-se a receber alguém para análise? Um dos grandes riscos presentes nessa situação é o da reprodução do desmentido: desmentido da realidade do que é narrado pelo analisando e desmentido de uma língua que lhe seria própria.

A esse respeito, Sabourin (1988) alerta para os perigos de o analista fazer uso de uma teoria ou de uma fantasia para ridicularizar a realidade psíquica do analisando. Quando isso acontece, a psicanálise agrava o desmentido da experiência infantil que já havia ocorrido por responsabilidade dos adultos. Desse modo, se é o desmentido de um adulto o decisivo no fenômeno traumático, consequentemente, é o desmentido pelo psicanalista o que pode provocar "passagens ao ato muito graves, por uma reprodução "pior do que o traumatismo original"' (p.154).

A fim de que o desmentido não se repita na situação analítica, é fundamental que haja confiança na relação entre analista e analisando, possibilitandose assim um contraste entre o presente e o que foi vivido no passado. A crítica de Ferenczi (1933/1992) se dirige a uma psicanálise puramente intelectual, insensível e pedagógica:

A situação analítica, essa fria reserva, a hipocrisia profissional e a antipatia a respeito do paciente que se dissimula por trás dela, e que o doente sente com todos os seus membros, não difere essencialmente do estado de coisas que outrora, ou seja, na infância, o fez adoecer. (p.100).

O paradoxal é que o risco de uma análise assim realizada é justamente o de produzir um "bom aluno", alguém que aceita docilmente as interpretações do analista e que é incapaz de criticá-lo. "Em vez de contradizer o analista, de acusá-lo de fracasso ou de cometer erros, os pacientes identificam-se com ele" (Ferenczi, 1933/1992, p. 98), assim como haviam se identificado anteriormente com o agressor da sua infância.

O saber excessivo - e delirante - do analista é, assim, um dos principais fatores que contribuem para a reprodução do desmentido na clínica. $\mathrm{O}$ analista acaba por se esquecer de reconhecer que há limites em seu saber, assim como de que há uma insuficiência em sua ajuda, algo que Ferenczi (1932/1990) chama de "falha analítica". Em contraposição a uma atitude de hipocrisia profissional, Ferenczi (1928/1992e) valoriza a modéstia do analista. Para isso é importante que este consiga reconhecer seus erros, de forma que o analisando possa confiar em sua sinceridade e franqueza. O fanatismo da interpretação seria algo extremamente nocivo, promovendo o esquecimento de que a técnica da interpretação é apenas um dos meios para se conhecer o estado psíquico do analisando, e não o objetivo principal da análise. Como a interpretação se restringe a certos detalhes, seria indispensável a "compreensão do conjunto do texto", uma vez que o mais importante é a consideração da situação analítica como um todo (Ferenczi, 1924/1993).

Nesse sentido, uma das preocupações constantes de Ferenczi recai sobre a formação do analista, já que, assim como adultos, devido a "pulsões malcontroladas", acabam por conduzir uma educação que deixa de respeitar os movimentos próprios da criança, também os analistas podem, no processo terapêutico, ter reações excessivas - seja no sentido de exigências de frustração muito rígidas, seja no de uma permissividade desmesurada (Ferenczi, 1930/1992b).

Como consequência de a análise didática adotada nas instituições de formação, na época, ter duração menor e não ter atingido grande profundidade, se comparada com uma análise terapêutica, criava-se a situação absurda de os pacientes serem mais bem analisados que os analistas (Ferenczi, 1933/1992). Era fundamental, nesse sentido, que os analistas pudessem reconhecer seus próprios afetos, uma vez que, alerta Ferenczi (1932/1990),

Não se deve descartar a ideia de que o hábito dos analistas de sempre procurar obstáculos na resistência dos pacientes, de um modo paranóide, de certa forma delirante, seja praticado injustamente, com fins de projeção ou para negar seus próprios complexos (p.59).

\section{A CLÍNICA PSICANALÍTICA E A ÉTICA DA HOSPITALIDADE}

A partir da teoria do trauma apresentada por Ferenczi, pode-se destacar a hospitalidade como um dos princípios fundamentais para uma ética do cuidado na psicanálise (Kupermann, 2009). A hospitalidade na clínica implica a possibilidade de reconhecer o analisando como um estrangeiro que 
possui uma língua estranha ao analista. Desse modo, é possível que se evite, na situação analítica, a reprodução do desmentido; ou seja, a língua do analisando não é desautorizada por outra que queira se colocar como legítima enunciadora da verdade, como língua total.

À guisa de ilustração da relação existente entre a hospitalidade e o uso da linguagem, podemos retomar aqui, acompanhando Derrida (2003), o caso de Sócrates condenado à morte, acusado de não reconhecer os deuses, de introduzir novos cultos e de corromper a juventude, tal como foi descrito por Platão em Apologia de Sócrates. Sócrates anuncia que, contra os mentirosos que o acusam, vai dizer somente o justo e o verdadeiro:

Mas não, por Zeus, Atenienses, não ouvireis discursos como o deles, aprimorados em nomes e verbos, em estilo florido; serão expressões espontâneas, nos termos que me ocorrerem.... a mesma linguagem que habitualmente emprego na praça, junto das bancas... Acontece que venho ao tribunal pela primeira vez aos setenta anos de idade; sinto-me assim completamente estrangeiro à linguagem do local. Se eu fosse de fato um estrangeiro, sem dúvida me desculparíeis o sotaque e o linguajar de minha criação; peço-vos nesta ocasião a mesma tolerância, que é de justiça a meu ver, para a minha linguagem (Platão, citado por Derrida, 2003, p.17).

Segundo Derrida (2003), Sócrates é acusado em uma língua que não fala (ou diz não falar), e deve defender-se nessa língua, a do direito e dos juízes; ele é, portanto, estrangeiro ao discurso de tribunal. Sócrates pede para ser tratado como estrangeiro, como se dissesse:

se eu fosse estrangeiro, vós aceitaríeis com mais tolerância que eu não fale como vós, que eu tenha meu idioma, minha maneira tão pouco técnica, tão pouco jurídica de falar, uma maneira que é ao mesmo tempo a mais popular e a mais filosófica (Derrida, 2003, p.19).

Do mesmo modo, o estrangeiro, que é desajeitado ao falar a língua do local, sempre se arrisca a ficar sem defesa diante da jurisdição do país que o acolhe ou o expulsa:

Ele deve pedir hospitalidade numa língua que, por definição, não é a sua, aquela imposta pelo dono da casa, o hospedeiro, o rei, o senhor, o poder, a nação, o Estado, o pai, etc. Estes lhe impõem a tradução em sua própria língua, e esta é a primeira violência (Derrida, 2003, p.15).

Neste sentido, Derrida (2003) questiona se, para podermos oferecer hospitalidade a alguém, devemos pedir que ele nos compreenda, que fale nossa língua, em todos os sentidos desse termo, pois (e esse é o paradoxo que se impõe), se o estrangeiro "já falasse nossa língua, com tudo o que isso implica, se nós já compartilhássemos tudo o que se compartilha com uma língua, o estrangeiro continuaria sendo um estrangeiro e dir-se-ia, a propósito dele, em asilo e em hospitalidade?" ( p.15).

Nos ensaios $A$ adaptação da família à criança e $A$ criança mal-acolhida e sua pulsão de morte Ferenczi aborda o tema da hospitalidade sob outra ótica: a de que o outro a ser recebido no seio da casa é o recémnascido.

A hospitalidade para com o infans, o bebê que não fala, tem uma particularidade, pois ela deve ser sempre uma hospitalidade absoluta ou incondicional. Ela pressupõe a exigência de oferecer a quem chega uma acolhida sem condições. Para Derrida (2003), a hospitalidade absoluta implica que abramos nossa casa ao outro desconhecido, que lhe cedamos lugar, que o deixemos “(...) chegar e ter um lugar no lugar que ofereço a ele", sem exigir dele reciprocidade (p. 24).

Ferenczi vai dar grande importância ao papel do ambiente e da família na constituição da subjetividade da criança. O recém-nascido já se encontraria fisiologicamente preparado para a transição que se opera no nascimento; mas para que essa transição aconteça da forma mais suave possível, será indispensável o acolhimento proporcionado pela adaptação que a família tem de realizar a fim de tornar bem-vindo esse novo hóspede:

No início da vida, intra e extra-uterina, os órgãos desenvolvem-se com uma abundância e uma rapidez surpreendentes - mas só em condições particularmente favoráveis de proteção do embrião e da criança. A criança deve ser levada, por um prodigioso dispêndio de amor, de ternura e de cuidados, a perdoar aos pais por terem-na posto no mundo sem lhe perguntar qual era sua intenção (Ferenczi, 1929/1992f, p.50).

O bebê encontrar-se-ia muito próximo de um estado de não-ser individual, para o qual corre o risco 
de deslizar, caso não encontre o "dispêndio de amor, de ternura e de cuidados" acima referido. É nesse estado que estaria, para Ferenczi (1931/1992d), a gênese do sentimento de autodestruição, uma vez que a criança que se sente abandonada perde todo o seu prazer de viver e volta sua pulsão de morte contra si mesma.

O olhar de Ferenczi, nesse momento da sua obra, recai não mais em uma pressuposta experiência individual do sujeito pulsional, mas na percepção de uma indiscernibilidade entre o bebê e o ambiente que o acolhe. Isso o leva a conferir ao fenômeno traumático um olhar genealógico (e não originário), interessado na compreensão do campo de forças da produção do patológico.

Por conta da indiscernibilidade entre bebê e ambiente, Ferenczi (1929/1992f) afirma:

\section{A "força vital" que resiste às dificuldades da vida não é, portanto, muito forte no nascimento; segundo parece, ela só se reforça após a imunização progressiva contra os atentados físicos e psíquicos, por meio de um tratamento e de uma educação conduzidos com tato (p.50).}

Fundamental para essa força vital é a criança poder usufruir a irresponsabilidade da infância, estado que traria a marca da ilusão de onipotência e da alegria de existir, por meio da qual ela constitui os impulsos positivos de vida e a possibilidade de brincar, de simbolizar e introjetar suas experiências de satisfação (Kupermann, 2009); porém a força vital pode ficar seriamente comprometida quando a criança é mal-acolhida em seu ambiente (Ferenczi, 1929f/1992), ou, como melhor sugere o título em alemão do ensaio de Ferenczi - "A criança malacolhida (Das unwillkommene Kind) e sua pulsão de morte"-, quando a criança é uma "hóspede não bemvinda" em sua família. Caso isso aconteça, as consequências para o sujeito podem ser que ele perca precocemente o gosto pela vida e que os menores acontecimentos sejam o bastante para suscitar uma paixão mortífera. O psicanalista, ao receber analisandos com essas características, deve estar atento para que possam desfrutar, talvez pela primeira vez em sua vida, da alegria criadora do brincar infantil, favorecendo, desse modo, a emergência de impulsos vitais positivos, fonte da continuidade do ser e do desejar e de razões para se continuar existindo.

\section{REFERÊNCIAS}

Benjamin, W. (2008). A tarefa-renúncia do tradutor. (S. Lages, Trad.). In L. Branco. (Org.), A tarefa do tradutor, de Walter Benjamin: quatro traduções para o português (pp. 66-81). Belo Horizonte: Fale/UFMG. (Original publicado em 1923).

Derrida J. (2006). Torres de Babel. (J. Barrento, Trad.). Belo Horizonte: UFMG.

Derrida, J. (2003). Questão do estrangeiro: vinda do estrangeiro. (A. Romane, Trad.). In J. Derrida, \& A. Dufourmantelle. Anne Dufourmantelle convida Jacques Derrida a falar da hospitalidade (pp. 5-65). São Paulo: Escuta.

Ferenczi S. (1992c). Reflexões sobre o trauma. (A. Cabral, Trad.). In Psicanálise IV (pp. 109-117). São Paulo: Martins Fontes. (Original publicado em 1934).

Ferenczi, S. (1990). Diário Clínico. (A. Cabral, Trad.). São Paulo: Martins Fontes. (Original escrito em 1932.)

Ferenczi, S. (1992). Confusão de língua entre os adultos e a criança. (A. Cabral, Trad.). In Psicanálise IV (pp. 97106). São Paulo: Martins Fontes. (Original publicado em 1933).

Ferenczi, S. (1992a). A adaptação da família à criança. (A. Cabral, Trad.). In Psicanálise IV (pp. 1-13). São Paulo: Martins Fontes. (Original publicado em 1928).

Ferenczi, S. (1992b). Princípios de relaxamento e neocatarse. (A. Cabral, Trad.). In Psicanálise IV (pp. 53-68). São Paulo: Martins Fontes. (Original publicado em 1930).

Ferenczi, S. (1992d). Análises de crianças em adultos. (A. Cabral, Trad.). In Psicanálise IV (pp. 69-83). São Paulo: Martins Fontes. (Original publicado em 1931).

Ferenczi, S. (1992e). Elasticidade da técnica psicanalítica. (A. Cabral, Trad.). In Psicanálise IV (pp. 25-36). São Paulo: Martins Fontes. (Original publicado em 1928).

Ferenczi, S. (1992f). A criança mal-acolhida e sua pulsão de morte. (A. Cabral, Trad.). In Psicanálise IV (pp. 4751). São Paulo: Martins Fontes. (Original publicado em 1929).

Ferenczi, S. (1993). Perspectivas da psicanálise. (A. Cabral, Trad.). In Psicanálise III (pp. 225-240). São Paulo: Martins Fontes. (Original publicado em 1924).

Haynal, A. (1995). A técnica em questão: controvérsias em psicanálise: de Freud e Ferenczi a Michael Balint. São Paulo: Casa do Psicólogo.

Kupermann, D. (2006). A progressão traumática: algumas consequências para a clínica na contemporaneidade. Percurso - revista de psicanálise, 18(36), pp. 25-32.

Kupermann, D. (2009). Princípios para uma ética do cuidado. Memória da psicanálise 3: Sándor Ferenczi: A ética do cuidado. São Paulo: Duetto Editorial.

Lacan, J. (1998). Função e campo da fala e da linguagem em psicanálise. (V. Ribeiro, Trad.). In Escritos (pp. 238-324). Rio de Janeiro: Jorge Zahar (Original publicado em 1953). 
Laplanche, J. (1988). Teoria da sedução generalizada. Porto Alegre: Artes Médicas.

Pinheiro, T. (1995). Ferenczi: do grito à palavra. Rio de Janeiro: Jorge Zahar.

Sabourin, P. (1988). Ferenczi: Paladino e grão-vizir secreto (L. Costa, Trad.). São Paulo: Martins Fontes. 